\title{
Validation of the Job Crafting Scale in Latin American Workers
}

\author{
Oscar Iván Gutiérrez-Carvajal ${ }^{1,2^{*}}$, Jean David Polo-Vargas ${ }^{1}$, Alba Ruth Vargas-Montealegre ${ }^{2}$, Marcos Zumárraga-Espinosa ${ }^{3}$, \\ Ximena Ramírez-Ocaña ${ }^{3}$, Valeria Segovia Marin ${ }^{3}$, and Lina Margarita Calderín Salgado ${ }^{1}$ \\ 1 Universidad del Norte, Barranquilla (Colombia) \\ 2 Universidad de Ibagué, Ibagué (Colombia) \\ 3 Universidad Politécnica Salesiana del Ecuador, Quito (Ecuador)
}

\begin{abstract}
Título: Validación de la escala Job Crafting en trabajadores latinoamericanos.

Resumen: En este estudio, se analizaron las propiedades psicométricas de la versión en español (Bakker et al., 2018) de la escala Job Crafting de Tims et al. (2012) en población latinoamericana. Aplicamos la escala a una muestra de 903 empleados (42.6\% mujeres y $57.4 \%$ hombres) de Colombia y Ecuador. Se examinaron la fiabilidad y la validez. Los resultados del análisis factorial confirmatorio mostraron un ajuste adecuado tanto en Colombia $(\mathrm{CFI}=.916, \mathrm{TLI}=.900, \mathrm{IFI}=.917, \mathrm{RMSEA}=.060)$ como en Ecuador $(\mathrm{CFI}=.918$, TLI $=.903, \mathrm{IFI}=.919, \mathrm{RMSEA}=.064)$, en la estructura de cuatro factores de la escala original. Se encontró evidencia de validación, relacionada con el criterio de bienestar psicológico, para las dimensiones de recursos estructurales crecientes y demandas desafiantes crecientes. La versión en español de la escala demuestra su utilidad para la investigación en el contexto latinoamericano.

Palabras clave: Reajuste del puesto de trabajo. Validación de escalas. Teoría de los recursos demandados por el trabajo. Bienestar psicológico. Proactividad.
\end{abstract}

\section{Introduction}

Job crafting (JC) has been defined as the initiatives taken by an employee to achieve their indicators or work objectives, according to their motivation and preferences (Wrzesniewski \& Dutton, 2001). JC is characterized, mainly, by the selfmodification of tasks and variables that intercede in the performance of the work; it does not contemplate the modification of the work in its entirety, but, rather, of some aspects, according to the motivation and initiative of the employee, and to the limits of their assignments (Berg \& Dutton, 2008).

The term was coined by Wrzesniewski \& Dutton in 2001, however, more than 20 years ago, Kulik and associates (1987) gave notions of what it is now considered to be JC, as they explained how employees redesigned their jobs from their initiative and without the participation of the administration. JC differs from job redesign in that employers do not agree to a change in working conditions (Hornung et al., 2010; Nadin et al., 2001), and it is a type of proactive work behavior initiated by the employee, taking advantage of a future situation, or taking control of it and causing a change (Parker \& Collins, 2010). Unlike other types of proactive behaviors, JC is aimed at improving work attitude, motivation, and their well-being (Tims et al., 2012).

There are several positions on JC and one of the most recognized is that of Tims et al. (2012), who proposed, and

* Correspondence address [Dirección para correspondencia]: Oscar Iván Gutiérrez Carvajal. Calle 51 No. 4B-52 Ibagué (Colombia).

E-mail: oscar.ivan.gutierrez@gmail.com

(Article received: 9-3-2021, revised: 30-6-2021, accepted: 1-7-2021)
Abstract: In this study, the psychometric properties of the Spanish version (Bakker et al., 2018) of the Job Crafting scale of Tims et al. (2012), was analyzed in a Latin American population. We applied the scale to a sample of 903 employees $(42.6 \%$ women \& $57.4 \%$ men) from Colombia and Ecuador. Reliability and validity were examined. The results of the confirmatory factor analysis showed an adequate fit both in Colombia (CFI $=.916$, TLI $=.900, \mathrm{IFI}=.917, \mathrm{RMSEA}=.060)$ and in Ecuador $(\mathrm{CFI}=.918, \mathrm{TLI}=$ .903 , IFI $=.919$, RMSEA $=.064)$, in the four-factor structure of the original scale. Evidence of validation, related to criterion for psychological wellbeing for the dimensions of increasing structural resources and increasing challenging demands, was found. The Spanish version of the scale demonstrates its usefulness for research in the Latin American context.

Keywords: Job crafting. Scale validation. Job-demand resources theory. Psychological well-being. Proactivity.

adjusted, the construct to the demand-resources model (Bakker \& Demerouti, 2007; Demerouti et al., 2001). Under this position, JC helps the employee find the balance between labor demands and labor resources, which can be functional to achieve good job performance and reduce psychological costs. Tims et al. (2012) propose that to change the level of demand-resource, and align them to the skills and needs, the employee can take four paths that are constituted in the dimensions of JC: increase structural resources, increase social resources, increase challenging demands, and reduce the level of hindering work demands.

Increased structural resources and increased social resources can buffer the effects of high job demands and can result in job engagement (Vogt et al., 2016). They have been shown to have an indirect effect on intention to leave (Lazarte, 2016), job performance (Bakker, 2015; Van Windergen et al., 2016), and workplace well-being (Slemp \& VellaBrodrick, 2104). Similarly, increasing challenging demands help work motivation, because employees experience tasks as a challenge, thereby stimulating the development of knowledge and skills (LePine et al., 2005). In this sense, creating challenging jobs can be a way to increase personal development and job satisfaction (Berg et al., 2008).

Regarding the decrease in hindering demands, Schaufeli et al. (2009) stated that prolonged exposure to overwhelming jobs that exceed abilities can have effects on health, such as emotional exhaustion. Therefore, it is important for the employee to find a way to reduce the demands that they consider to be hampering to be satisfied, enjoy good health, and to perform well. 
In 2012, Tims et al. developed and validated the 21-item Job Crafting Scale (JCS) to measure JC in a sample of 1,181 employees in the Netherlands. The JCS comprises six items for the dimension of reduction of hindering demands and five for the others. The internal consistency by Cronbach's alpha ranged between questionable to acceptable $(\alpha=.75$ to $\alpha=.82)$, and the Confirmatory Factor Analysis showed acceptable results $(C F I=.89 ; T L I=.89 ; I F I=.90 ; R M S E A=$ .04). Likewise, in the validation, they found correlations between the dimensions of the JCS with proactive personality $(r=.17$ to .46$)$, personal initiative $(r=.17$ to .55$)$; engage- ment $(r=-.19$ to .46$)$; and yield $(r=-.10$ to .40$)$. The inverse correlations and those with lower effects correspond to the dimension of reduction of hindering demands.

The JCS has been tested on different samples of employees from various countries and has proven its validity. The dimensions of increased structural resources, increased social resources, and increased challenging demands were validated in all studies; while the decrease in hindering demands was eliminated in two of the studies, due to low statistical representation (Chinelato et al., 2015; Cenciotti et al., 2016).

\section{Table 1}

List of studies on the validation of Job Crafting Scale.

\begin{tabular}{|c|c|c|c|}
\hline Author(s) & Country & Number of items and Cronbach's alpha & CFA fit indexes \\
\hline Cenciotti et ál., 2016 & Italy & $\mathrm{ARE}=4 ; \alpha .81 . \mathrm{ARS}=4 ; \alpha .74 . \mathrm{ADD}=4 ; \alpha .78$ & $C F I=.93 ; T L I=.91 ; R M S E A=.08$. \\
\hline $\begin{array}{l}\text { Chinelato, Ferrerira, \& } \\
\text { Valentini, } 2015\end{array}$ & Brazil & $\mathrm{ARE}=4 ; \alpha .71 . \mathrm{ARS}=4 ; \alpha .78 . \mathrm{ADD}=5 ; \alpha .77$ & $C F I=.95 ; T L I=.94 ; R M S E A=.06$. \\
\hline Eguchi et ál. (2016) & Japan & $\mathrm{ARE}=5 ; \alpha .90 . \mathrm{DDO}: 6 ; \alpha .80 . \mathrm{ARS}=5 ; \alpha .76 . \mathrm{ADD}=5 ; \alpha .84$ & $\begin{array}{l}G F I=.91 ; P G F I=.70 ; \\
N N F I=.90 ; C F I=.94 \\
P N F I=0.77 ; \text { RMSE } A=.06\end{array}$ \\
\hline Gupta \& Shifali, 2019 & India & $\mathrm{ARE}=5 ; \alpha .82 . \mathrm{DDO}: 6 ; \alpha .79 . \mathrm{ARS}=5 ; \alpha .77 . \mathrm{ADD}=4 ; \alpha .75$ & $\begin{array}{l}C F I=.955 ; G F I=.916 ; A G F I=.892 ; \\
R M S E A=.036 .\end{array}$ \\
\hline Lichtenthaler \& & Germany & $\mathrm{ARE}=5 ; \alpha .76$ a $77 . \mathrm{ARS}=5 ; \alpha .79$ a $83 . \mathrm{ADD}=5 ; \alpha .87$ a 88 & RMSE $A=.07$ \\
\hline Fischbach, 2016 & & DDO: $6 ; \alpha .79$ a 81 & $\begin{array}{l}T L I=.89 \\
C F I=.91 \\
I F I=.91\end{array}$ \\
\hline $\begin{array}{l}\text { Sora, Caballero, \& } \\
\text { García-Budas, } 2018\end{array}$ & Spain & $\mathrm{ARE}=3 ; \alpha .75 . \mathrm{DDO}: 3 ; \alpha .64 . \mathrm{ARS}=3 ; \alpha .78 . \mathrm{ADD}=3 ; \alpha .77$ & $\begin{array}{l}A G F I=.94 ; N N F I=.93 ; \\
S R M R=.05 ; R M S E A=.06 .\end{array}$ \\
\hline
\end{tabular}

$\overline{\mathrm{ARE}}=$ increase of structural resources, ARS $=$ increase of social resources, ADD $=$ increase of challenging demands, DDO $=$ decrease of hindering demands, $r=$ Pearson correlation coefficient; $\alpha$ : Cronbach's alpha internal consistency; GFI = fit index; CFI = comparative fit index; NFI = normalized fit index; RMSEA = Root mean square error of approximation.

We review six studies on the validation of JCS (see table 1). The number of items on the JCS is constant for almost all the studies, except for the study by Sora et al. (2018), who presented a 12-item version. Internal consistency using Cronbach's alpha and confirmatory factor analysis (CFA) were acceptable in all studies, and correlations with proactivity, personal initiative, engagement, positive psychological capital, positive affect, and work performance were shown (Chinelato et al., 2015; Bakker et al., 2018). The JCS has proven its validity in several countries, however, there were not any validations of the JCS in Spanish-speaking Latin American countries.

Brazil was the only Latin American country where the JCS was validated, and it was done in Portuguese (Chinelato et al., 2015), however, the original model of the four factors was not corroborated, and the dimension of decrease in demands was removed. Thus, Bakker \& Demerouti (2007) explain that different jobs involve different types of specifications and levels of demands and resources, which could imply that JC can also vary. Likewise, cultural differences can also interfere with JC (Erez, 2010; Bohnlein \& Baum, 2020), due to the characterization of labor relations, the system of autonomous groups, centralization, autonomy, and authority.

The JCS was adapted and validated to Spanish by Bakker et al. (2018), who demonstrated the reliability and factorial validity of the JCS with 21 items in four factors. Cronbach's alpha was between $\alpha .75$ and $\alpha .79$ and there were indices, in the CFA, that were similar to those of the original version $(C F I=.858 ;$ TLI $=.838 ;$ IFI $=.860 ;$ RMSE $A=.067)$. Likewise, they found correlations with other constructs such as proactivity $(\mathrm{r}=.05-.50)$, and the dimensions of engagement, such as vigor $(\mathrm{r}=-.14$ to .50$)$, dedication $(r=-.13$ to .37 ), and absorption ( $r=.-15$ to $r=.38)$. As in the original version, the inverse correlations and those with lesser effects correspond to the dimension of decrease of hindering demands.

Up to the date of this review, there were not validations of the Spanish version of the JCS for Latin America. In this context, this instrumental study aims to provide evidence of the reliability and validity of the Spanish version of the JCS in workers from Colombia and Ecuador.

\section{Method}

\section{Participants}

It was a non-probabilistic sample of 903 workers who voluntarily agreed to participate in the study and that correspond to Latin American companies (five in Ecuador and six in Colombia), considering their nature and the scope of the 
research contributions, since they are applied to other companies in other sectors, which would allow the results to be analyzed in contrast to other economic sectors.

The employees were women (42.6\%) and men (57.4\%) of various positions and hierarchical levels of public and private organizations in Colombia (67.7\%) and Ecuador (32.4\%). However, 888 (98\%) of the responses were completed and the analysis was based on these. The participants were employees of various positions corresponding to operational $(29.7 \%)$, assistance $(35.5 \%)$, professional $(21.7 \%)$, middle management $(12.1 \%)$, and senior management $(1 \%)$ levels. The organizations to which the participants belonged were from the educational sectors $(52.6 \%)$, manufacturing $(9.6 \%)$, mass consumption $(7.1 \%)$ consulting $(4.6 \%)$, transportation $(2 \%)$, retail $(0.8 \%)$, advertising and marketing $(1 \%)$, financial $(1.2 \%)$, telecommunications $(1.4 \%)$, health $(4.7 \%)$, and others $(15 \%)$. Although the education sector had the highest percentage, it was made sure that there were similar amounts of positions at all levels, and that the sample was not concentrated on teachers. The age of the participants was $\mathrm{M}=35.8 ; \mathrm{S}=11.1$ years, and their levels of studies were: bachelor $(17.1 \%)$, technician or technologist $(24.6 \%)$, professional $(28.2 \%)$, specialist $(10.9 \%)$, magister $(16.7 \%)$, and doctorate $(2.5 \%)$. Seniority in the organization was $M=81.6 ; S=87.8(1 ; 480)$ months.

\section{Instruments}

The Spanish version of the Job Crafting Scale (SJCS): The Spanish version of the JCS developed by Bakker et al. (2018), which consists of 21 items grouped in four dimensions and whose properties were previously described, was used. The SJCS is answered on a seven-point scale from never to forever. Examples of the items are: "I try to develop my capacities" (increase in structural resources), "I make sure that my work is less mentally intense" (decrease in hindering demands), "I wonder if my supervisor is satisfied with my work "(increase in social resources)," If there are new developments, I am one of the first to learn about them, and to try them "(increase in challenging demands).

Psychological well-being: The Spanish version (Díaz, 2007) of the psychological well-being scale (Ryff, 1989) was used. The psychological well-being scale consists of 39 items (example "I am clear about the direction and goal of my life"), which are grouped into six dimensions (autonomy, personal growth, positive relationships, self-acceptance, mastery of the environment, and purpose of life). The response form of this questionnaire is a six-point Likert scale that ranges from "totally disagree" (1) to "totally agree" (6). This scale has been widely used and proven in its validity and reliability (Díaz, 2007; Keyes \& Grzywacz, 2005), and in samples in Latin America (Ibañez \& Madiarraga, 2017). The internal consistency of the scale for this study was $\alpha=.91$.

\section{Procedure}

To implement the Spanish version of the JCS, the authors invited companies to participate through contact with the heads of human resources and management, who then asked their employees to participate in the study. Each company was visited to meet with the participants, explain the objectives of the investigation, and to request their consent to maintain due ethical process. Application was made through virtual or paper questionnaires, with the accompaniment of members of the research team. Databases were created and there was a process to check that the responses of the participants were complete and that there was no tendency to mark a single number in the questionnaire.

\section{Data Analysis}

The empirical validation strategy of the SJCS for the contexts of Colombia and Ecuador consists of the following phases: a) analysis of the psychometric properties of the instrument for each country on its own, taking the factorial model proposed by Bakker et al. (2018) based on the adaptation work carried out for the Spanish context as a reference; b) evaluation of construct measurement invariance between the samples from Ecuador and Colombia, approached simultaneously; and c) evaluation of criterial validation by correlating the SJCS with psychological well-being.

The construct validity of the SJCS was examined by Confirmatory Factor Analysis (CFA). Given that the instrument uses a response format of at least 5 points, and the set of items reports evidence of multivariate normality in the two samples $^{1}$, the different estimates were made by the maximum likelihood method (Lloret-Segura et al., 2014; Motl \& Conroy, 2000). However, to have more reliable results, the maximum likelihood method was complemented with a resampling process (based on 2000 bootstrap samples), thus obtaining more accurate standard errors and $\mathrm{p}$-values concerning the estimation of parameters (Byrne, 2010).

To test the adequacy of the four-factor model to the data of each sample (Colombia and Ecuador), the following goodness of fit indicators were considered: chi-square test $\left(\chi^{2}\right)$; ratio between chi-square and degrees of freedom $\left(\chi^{2}\right)$

\footnotetext{
${ }^{1}$ As a criterion for the evaluation of univariate normality, it was considered that absolute values of kurtosis lower than 10 , and asymmetry below 3 , indicate the absence of substantial deviations from a normal distribution (Kline, 2005). In this regard, all the items of the SJCS meet the normality criteria established in both the Colombian and Ecuadorian samples. For the multivariate normality analysis, the Mardia test was used (Bollen, 1989). According to this test, and following the approach of Raykov and Marcoulides (2008), there is multivariate normality when the Mardia multivariate kurtosis coefficient $(\mathrm{CMM})$ does not exceed the value of $\mathrm{p}(\mathrm{p}+2)$, where $\mathrm{p}$ is the number of observed variables or, in this case, the items of the instrument. This condition is fulfilled for the data from Colombia $(\mathrm{CMM}=264.36)$ and Ecuador $(\mathrm{CMM}=109.24)$, given that $\mathrm{p}(\mathrm{p}+2)=483$. Finally, the evidence provided by the specialized literature suggests that the Maximum likelihood method is quite robust in cases characterized by the use of ordered categorical data and violation of the multivariate normality assumption (Hutchinson and Olmos, 1998; Nevitt and Hancock, 2001; Stevanovic, 2009).
} 
$g \downarrow)$; parsimonious goodness-of-fit index (PGFI); TuckerLewis index (TLI); Incremental Adjustment Index (IFI); comparative fit index (CFI); root mean square residual approximation (RMSEA). The referential minimums that reflect an acceptable adjustment are: TLI, IFI, CFI $\geq .90$; RMSE $A \leq .08 ; P G F I \geq .50 ; \chi^{2} / g l \leq 3$ (Beauducel \& Wittmann, 2005; Byrne, 2010; Schermelleh-Engel et al., 2003; Van de Schoot et al., 2012).

Regarding the $\chi^{2}$ test, what would be expected would be a non-significant result $(\phi>.05)$, accepting the null hypothesis that the covariance matrix resulted from the factorial model is equal to the population covariance matrix $\left(\sum[\theta]=\right.$ $2)$. However, achieving this result is very difficult in practice, both because of the sensitivity of this test to increases in the sample size, and because of the exactness of the described hypothesis (Barrett, 2007; Steiger, 2007). For these stated reasons, the reporting of $\chi^{2}$ and $\chi^{2} / g l$ has a purely informative function.

After carrying out an initial CFA by country, the resulting modification indices were reviewed, in order to detect possibilities of improvement for the adjustment of the model. It should be noted that this course of action is viable only when there is adequate conceptual support for the respecification about to be introduced (Medrano \& MuñozNavarro, 2017).

In a second moment, the measurement equivalence of the SJCS was analyzed. This is a systematic testing process focused on defining whether a specific construct is capable of preserving its psychometric properties, between groups, or different moments (Putnick \& Bornstein, 2016). From a cross-country approach, it consists of determining whether the set of indicators/items that make up an instrument can capture or measure the same psychological construct, with the same factorial structure, in different cultural settings (Milfont \& Fischer, 2010). Generally, the measurement invariance test includes the following components: configural invariance, metric invariance, scalar invariance, inter-factorial covariance invariance, and factorial variance invariance (Byrne, 2010; Cheung \& Rensvold, 2002; Gregorich, 2006; Putnick \& Bornstein, 2016).

We executed the Multigroup Confirmatory Factor Analysis (MGCFA) technique. We based on the formulation of nested models, characterized by sequentially adding constraints to the starting factorial model (Milfont \& Fischer, 2010). Along with this, the adjustment of each model was simultaneously accomplished, concerning the samples of interest. We contrasted each new constriction with previous models, to verify whether the quality of the fit does not deteriorate due to the introduced changes. Thus, the nonexistence of significant variations in terms of goodness of fit was assumed as an indicator of invariance for the aspect of the construct being evaluated.

The sequence of nested models began with model 1 (configural invariance), which simultaneously applies the modified factorial model to the samples from Colombia and Ecuador, leaving the parameters to be freely estimated for each of them. Model 2 (metric invariance) restricts the factor loadings to be the same across countries. Model 3 (scalar invariance) adds an equality constraint for the intercepts of the items. Model 4 (invariance of inter-factorial covariances) requires that the covariances between latent factors be equivalent for both samples. Model 5 (invariance of factorial variances) makes the variances of the latent factors equal in both the Colombian and Ecuadorian cases. The models were compared based on the differences of the following goodness of fit indices: chi-square $\left(\chi^{2}\right), C F I$ and RMSE $A$.

Additionally, the validation of the criteria with the correlations between the dimensions of the SJCS with psychological well-being was studied, because JC is theoretically expected to have effects on aspects such as motivation and the well-being of employees.

The statistical analyzes were carried out with the statistical software SPPS-23® and AMOS-23®.

\section{Results}

\section{Psychometric Properties of the SJCS: Colombia and Ecuador}

Table 2 shows the results of the CFA for both, the original factorial model, and the modified model, according to the country. In the case of the modified model, covariances were incorporated between the measurement errors of the following items: 6 and 7 (COL $[r=.76 ; p<.001]$; ECU $[r=$ $.60 ; p<.001]) ; 8$ and 9 (COL $[r=.57 ; \mathrm{p}<.001]$; ECU $[r=$ $.44 ; p<.001]) ; 15$ and 16 (COL $[r=.26 ; p<.001]$; ECU $[r=$ .33 ; $\mathrm{p}<.001]) ; 12$ and 15 (COL $[r=-.32 ; p<.001]$; ECU $[r=$ $-.23 ; p<.05]) ; 14$ and 15 (COL $[r=-.22 ; p<.01]$; ECU $[r=$ $.23 ; p<.05]) ; 20$ and 21 (COL $[r=.09 ; p<.05]$; ECU $[r=.27$; $p<.001])$. Since these are covariances that do not operate between items of different dimensions, it is possible to justify their addition for reasons of redundancy or content overlap, in addition to constituting a strategy already used to adapt the JC scale in other non-Spanish-speaking contexts (Byrne, 2008; Bakker et al., 2018).

Table 2

CFA per country. Original and modified models.

\begin{tabular}{|c|c|c|c|c|}
\hline \multirow[b]{2}{*}{$\begin{array}{l}\text { Goodness-of-fit } \\
\text { indexes }\end{array}$} & \multicolumn{2}{|c|}{ Colombia } & \multicolumn{2}{|c|}{ Ecuador } \\
\hline & $\begin{array}{c}\text { Original } \\
\text { model }\end{array}$ & $\begin{array}{l}\text { Modified } \\
\text { model }\end{array}$ & $\begin{array}{l}\text { Original } \\
\text { model }\end{array}$ & $\begin{array}{l}\text { Modified } \\
\text { model }\end{array}$ \\
\hline$\overline{\chi^{2}}$ & 1245.63 & 575.69 & 587.42 & 374.71 \\
\hline$d f$ & 183 & 177 & 183 & 177 \\
\hline p-value & .0001 & .0001 & .0001 & .0001 \\
\hline$\chi^{2 / g l}$ & 6.81 & 3.25 & 3.21 & 2.12 \\
\hline PGFI & .654 & .704 & .656 & .674 \\
\hline$T L I$ & .743 & .900 & .808 & .903 \\
\hline$I F I$ & .777 & .917 & .835 & .919 \\
\hline CFI & .776 & .916 & .833 & .918 \\
\hline RMSEA & .097 & .060 & .090 & .064 \\
\hline$N$ & \multicolumn{2}{|c|}{617} & \multicolumn{2}{|c|}{271} \\
\hline
\end{tabular}

Note. $\chi^{2}=$ Chi-square, $p=$ p-value, $\mathrm{df}=$ degrees of freedom, PGFI $=$ parsimony goodness fit index, TLI $=$ Tucker-Lewis coefficient, IFI = incremental fit index, $\mathrm{CFI}=$ comparative fit index, $\mathrm{RMSEA}=$ root mean square error of approximation. 
On the other hand, although the covariances between the errors of items 6-7, 8-9 and 15-16 agree with the adjustments made by Bakker et al. (2018) for the case of Spain, the remaining covariances favor the adjustment of the construct for the Colombian and Ecuadorian context, suggesting, in the first instance, that these are additional specifications valid for the Andean zone, and their relevance to other countries of the region. That said, the analyzed indicators improve notably with the modified version of the model, showing an acceptable fit for the data of each country.

Table 3 shows the estimation of factor loads of the modified model for the data of Colombia and Ecuador. For its part, Table 4 presents the inter-factorial correlations of the model. As can be seen, there is no high and consistent intercorrelation between the dimensions of the SJCS (certain correlations are not even significant), implying that the use of global scores on the SJCS is not highly recommended (Cassidy, 2016). Being more pertinent, for analytical purposes, to use scores by subscale to measure the dimensions in which work redesign behaviors are disaggregated, in such a way that differentiated profiles, or sets of variables that are related to each job modality, can be identified crafting. Additionally, the reported inter-factorial association pattern also coincides with the findings of Bakker et al. (2018) for the Spanish case.

Table 3

Factor loads of the modified model. Colombia y Ecuador.

\begin{tabular}{lll} 
& \multicolumn{1}{c}{ F1 } & F2 \\
\cline { 2 - 2 } \multicolumn{1}{c|}{ Ítems } & COL ECU COL ECU COL ECU COL ECU \\
\hline Factor 1: Increase of structural resources & & \\
1.- I try to develop my abilities & .805 .774 \\
2.- I try to develop my professional career & .767 .806 \\
3.- I try to learn new things at work & .859 .871 \\
4.- I make sure that I can use my abilities to their maximum. & .762 .776 \\
5.- I decide, on my own, how to do things & .230 .409
\end{tabular}

Factor 2: Decrease of hindering demands

6.- I make sure my work is less intense, mentally

$.467 \quad .468$

7.- I make sure my work is less intense, emotionally

$.469 \quad .498$

8.- I can manage my work, so I make sure I try to minimize contact with people whose problems affect me, emotionally

9.- I organize my work so I minimize contact with people with unrealistic expectations

10.- I try to make sure I do not have to make difficult choices at work

11.-I organize my work, so I do not have to concentrate for a long period of time $.676 \quad .750$

Factor 3: Increase of social resources

12.- I ask my supervisor to coach me

13.- I wonder if my supervisor is satisfied with my work

14.- I look at my supervisor for inspiration

15.- I ask others for feedback on my work performance

16- I ask my colleagues for advice

Factor 4: Increase of challenging demands

17.- When there is an interesting project, I volunteer to work on it

18.- If there are new developments, I am one of the first to learn about them, and to try them.

19.- Not having much to do at work is an opportunity to start new projects

20.- I regularly do additional work even though I do not get paid extra for it

21.- I try to make work harder, to analyze the underlying relationships between its various aspects

Note: Standardized factor loads are reported, $p<.001$ for all cases. $\mathrm{COL}=$ Colombia, ECU $=$ Ecuador

Table 4

Correlations between factors of the modified model. Colombia and Ecuador

\begin{tabular}{|c|c|c|c|c|c|c|c|c|}
\hline & \multicolumn{2}{|c|}{ F1 } & \multicolumn{2}{|c|}{$\mathrm{F} 2$} & \multicolumn{2}{|c|}{ F3 } & \multicolumn{2}{|c|}{$\mathrm{F} 4$} \\
\hline & COL & ECU & COL & ECU & COL & ECU & COL & ECU \\
\hline Factor 1: Increase of structural resources & - & - & - & - & - & - & - & - \\
\hline Factor 2: Decrease of hindering demands & .009 & .043 & - & - & - & - & - & - \\
\hline Factor 3: Increase of social resources & $.135^{* *}$ & .123 & $.290^{* * *}$ & $.449 * * *$ & - & - & - & - \\
\hline Factor 4: Increase of challenging demands & $.584 * * *$ & $.535^{* * *}$ & .064 & .094 & $.424 * * *$ & $.358^{* * *}$ & - & - \\
\hline Psychological well-being & $.312^{* *}$ & $.372^{* *}$ & $-.237^{* *}$ & $-.197^{* *}$ & -.052 & -.049 & $.289^{* *}$ & $.400^{*}$ \\
\hline
\end{tabular}

Note: ${ }^{* * *} p<.001 ; * * p<.01 . \mathrm{COL}=$ Colombia, ECU = Ecuador

Regarding the reliability analysis, the Cronbach's alpha coefficient $(\alpha)$ was used to evaluate the internal consistency of the instrument and its subscales. Values above .60 are considered acceptable, greater than .70 satisfactory (Church- 
ill, 1979; Oviedo \& Arias, 2005). For more general reliability analysis, we used McDonald's Omega coefficient ( $\omega)$. In this case, the referential cut-off points suggest that values above
.65 are acceptable (Ventura-León and Caycho-Rodríguez, 2017).

Table 5

Cronbach's Alpha (a) / McDonald's Omega (w) of the SJCS and its components. Colombia and Ecuador.

\begin{tabular}{|c|c|c|c|c|}
\hline & \multicolumn{2}{|c|}{$\alpha$} & \multicolumn{2}{|c|}{$\omega$} \\
\hline & Colombia & Ecuador & Colombia & Ecuador \\
\hline Factor 1: Increase structural job resources & .69 & .82 & .70 & .82 \\
\hline Factor 2: Decrease hinderning job demands & .82 & .84 & .71 & .77 \\
\hline Factor 3: Increase social job resources & .73 & .80 & .78 & .78 \\
\hline Factor 4: Increase challenge demands & .68 & .78 & .66 & .74 \\
\hline Total Job Crafting & .80 & .85 & .90 & .93 \\
\hline
\end{tabular}

As Table 5 indicates, all the factors of the SJCS present acceptable $\alpha$ values, and except for factors 1 and 4 for the Colombian case, all the subscales report satisfactory levels of internal consistency $(\alpha>$.70). Regarding the coefficient $\omega$, all the subscales of the SJCS present acceptable levels of reliability $(\omega>.65)$ in Colombia and Ecuador.

\section{Evaluation of the Cultural Invariance of the SJCS}

The chi-square difference test $(\Delta \chi 2)$ was carried out, and it had a non-significant result $(>.05)$, which denotes intergroup equivalence of the analyzed component, while for the rest of the indicators the recommended invariance criteria are the following: $\triangle \mathrm{CFI}>-.01$ and $\triangle \mathrm{RMSEA}<.015$ (Chen, 2007; Vecchione et al., 2014; Zumárraga-Espinosa, 2020). With model 1 (configural invariance) as the starting point, the rest of the models were compared according to the next pattern: 2 vs $1 ; 3$ vs 2; 4 vs 2; 5 vs 2 (Cheung \& Rensvold, 2002). Finally, given that the samples from Colombia and Ecuador do not share the same size, they were balanced, as suggested by Yoon \& Lai (2018), for which a random subsample was extracted from the Colombian sample with a size equivalent to the Ecuadorian sample $(N=271)^{2}$. The results of the MGCFA are shown in Table 6.

Table 6

Measurement invariance analysis of the SJCS between Colombia and Ecuador.

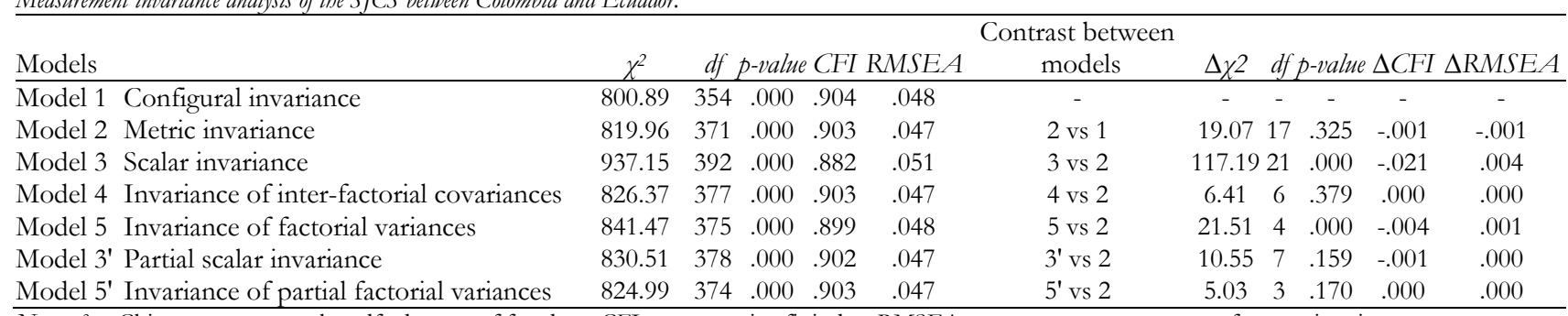

Note. $\chi^{2}=$ Chi-square, $p=$ p-value, $\mathrm{df}=$ degrees of freedom, CFI=comparative fit index, RMSEA= root mean square error of approximation.

The configural and metric invariance tests reveal satisfactory results, confirming weak factor equivalence between countries for the instrument, and the established measurement model. Likewise, the covariances between the job crafting dimensions are equivalently correlated in the two samples. Both, for the scalar invariance and inter-factorial variances analysis, the results indicate a lack of total equivalence between countries. Therefore, the sources of variation were identified in order to carry out partial invariance tests (Yoo, 2002). To do this, the intercepts that significantly differed between countries in the case of scalar invariance were isolated, and the fit of model 5 was tested, keeping the variances of one factor constant at a time, in order to identify the job crafting dimension whose variance is modified when moving from one cultural context to the other. The inter-

2 This methodological course of action is compatible with recent work by Borgogna, Brenner, and McDermott (2021), Buratta, Delvecchio, Germani, and Mazzeschi (2020), among others. cepts that do not significantly differ between countries correspond to items $5,6,8,12,13,15,21$, so only those intercepts were equated to test the presence of partial scalar invariance (model 3'), obtaining favorable results. Partial invariance of factorial variances is also verified once the equivalence constraint is imposed for the variances of F2, F3, and $\mathrm{F} 4$, leaving the variance of F1 (source of variation) to be freely estimated between samples.

To sum up, the developed MGCFA allows for the conclusion that the job crafting construct, defined by the modified factorial model, largely preserves its psychometric properties between the contexts of Colombia and Ecuador. In this sense, the SJCS has configural, metrical, and interfactorial covariance invariance, as well as scalar partial invariance and partial invariance at the level of latent factor variances. Configural invariance implies that Colombians and Ecuadorians assign equivalent meanings to the items on the SJCS, consequently making similar distinctions between the 
dimensions or modalities of the work redesign behavior. That is, the same item-factor associations are made. Metric invariance, on the other hand, indicates that the magnitude with which each item captures the factor that corresponds to it, is the same in both countries. Similarly, the dimensions of job crafting are correlated in an analogous way between countries. Although there is no total scalar invariance, the fact of having at least one invariant intercept for each factor of the SJCS (partial invariance), makes it possible for the means of the latent factors to be comparable between countries (Vecchione et al., 2014). Finally, only the variance of F1 (increase of structural employment resources) is significantly modified between Colombia and Ecuador. From what has been described, it is extracted that the JC scale has an adequate cultural adaptability that enables its application in the countries object of study.

\section{Criterion-related Validation}

A correlation test between the dimensions of the SJCS and the scale of psychological well-being was performed (see table No. 4). The results showed that the dimensions of increasing structural resources and increasing challenging demands were correlated with psychological well-being; however, the increase in social resources was not. On the contrary, the dimension of decrease of the hindering demands was negatively correlated with psychological well-being. These results occurred consistently in both countries.

\section{Discussion}

The study aimed to validate the Spanish version (Bakker et al., 2018) of the Job Crafting scale (Tims et al., 2012), in the Colombian and Ecuadorian contexts, theoretically based on the DLR theory of resources and labor demands (Tims \& Bakker, 2010; Tims et al., 2012; Tims et al., 2013) where, the worker can redesign his work, in order to reduce pressures, increase his resources of organizational support, and increase his work challenges (Salessi, 2020).

Wrzesniewski \& Dutton (2001) cited by (Tims et al., 2014) have argued that "workers can, and do, form the boundaries of their jobs and create a work environment that adjusts to their preferences, skills, and competencies", this highlights a proactive approach to instill in employees. Therefore, within this perspective, “job creation can be an interesting strategy used by workers to stay or participate in their work and, as a consequence, remain valuable for the organization" (Tims et al., 2014).

Studies maintain that workers who have a job with greater openness to recursion are more likely to participate in their work and generate a greater commitment to it, as mentioned by Crawford et al. (2010) and Halbesleben (2010), and cited by Tims et al. (2014). Similarly, it has been shown that "work commitment is positively associated with individual and organizational performance" (Lu et al., 2014). Thus, opening the job to adaptation through the empowerment of the worker via the practice of job crafting, can positively impact the development of engagement, and boost the level of performance of the collaborators within the organization.

Job crafting can be applied as a practice in current organizations, which can mean progress in relation to issues such as employee satisfaction and commitment, because, as highlighted (Schaufeli et al., 2002) workers with "freedom of decision about how and when to work, who can use various skills, and can rely on colleagues and others, are more likely to experience this state of mind of positive satisfaction". Even studies carried out at an international level (Rich et al., 2010; Xanthopoulou et al., 2009), as cited by Lu et al. (2014), have suggested that "organizations could promote the work commitment of workers by creating challenging environments and resourceful work. In this sense, job crafting could become a way to motivate and retain, as an organizational strategy, when other resources (monetary awards, etc.) are limited (Salessi, 2020).

The psychometric tests performed on the SJCS show that it is a valid and reliable instrument for its application in the contexts of Colombia and Ecuador. Likewise, it is corroborated that the factorial model proposed by Bakker et al. (2018), based on their analysis of the Spanish environment, is appropriate for measuring job crafting behaviors in the countries studied here. Therefore, it is an instrument that measures job crafting as a multidimensional construct made up of four subscales: a) increase in structural employment resources; b) decrease in hindering work demands; c) increased social resources for employment and d) growing demand for challenges at work.

Complementarily, the results regarding the invariance of measurement indicate that the SJCS significantly preserves its psychometric properties when moving from the Colombian to the Ecuadorian context. Almost all of the elements of the job crafting construct maintain equivalence between countries (configural, metrical, inter-factorial covariance invariance), with the exception of the scalar invariance and factorial variance invariance tests, although, partial invariance could be found in them. This allows for the conclusion that the interpretation and meanings attributed by workers from Colombia and Ecuador to the set of items of the instrument are similar, allowing them to capture, consequently, a highly equivalent construct. In this way, the instrument items operate as indicators of the same job crafting dimensions, in addition to measuring them in an equivalent way, which, together with the rest of the forms of variance found, suggests that the measurements made with the JC scale are comparable between the analyzed countries.

Regarding the criterion-related validation, which we verified with the correlation with the psychological well-being scale, it was found that the dimensions of the SJCS relate differently to psychological well-being. As expected, the dimensions of increasing structural resources and challenges were positively related to psychological well-being, which can be explained because they can generate motivation and satisfaction, while avoiding work-related stress situations. However, 
the dimension of increase in social resources was not related to psychological well-being, and the dimension of decrease in impeding demands was negatively related. These findings are consistent with the results of previous studies in different samples where the dimensions of increasing structural resources and challenges are positively related to well-being and the dimension of decrease in impeding demands was negatively related with well-being (Lichtenthaler \& Fischbach, 2019); however, we add evidence on the relationship between job crafting and psychological wellbeing (Ryff, 1989 cited by Díaz, 2007).

Among the limitations of the study, the need to complete the exposed results with concurrent validity tests that contrast the measurements of the SJCS with other valid instruments for the assessment of this construct stands out. We carried out a criterion validity analysis based on the theoretical association between job crafting and psychological wellbeing, but it constitutes an exploration of the nomological validity of the SJCS in this context (Hagger, Gucciardi \& Chatzisarantis, 2017). It remains to evaluate the nomological validity of the instrument considering a more extensive nomological network. So that it can be verified whether this construct (and its dimensions) is empirically connected with other psychological variables associated at a theoretical level, and whether or not these relationships are modified by different cultural settings.

Future research from larger and more representative samples is also required. A point that acquires special relevance, given the inclusion of covariances between residuals in the validation process of the SJCS, for the studied contexts. This strategy was selected for reasons of methodological rigor, because although the correlations between measurement errors usually operate as indicators of redundant information, thus supporting the elimination of items to increase the psychometric performance of the instrument (Domínguez-Lara, 2019), the limitations of the used samples require a greater verification of the re-specifications introduced, so that if the SJCS is refined, this action can be consistent. On the other hand, we consider it pertinent to develop studies that review the possibility of having objective job crafting measures that are not self-reported, as occurs with

\section{References}

Bakker, A., (2015). Top down and bottom up interventions to increase work engagement. In P. Hartung, M. Savickas, \& B. Walsh, AP A Handbook of Career Intervention: Vo2. Applications (427-438). Washington, DC: American Psychological Association. https://doi.org/10.1037/14439031

Bakker, A., \& Demerouti, E. (2007). The job demands-resources model: State of the the art. Journal of Managerial Psuchology, 22, 309-328. https://doi.org/10.1108/02683940710733115

Bakker, A., Ficapal-Cusi, P., Torrent-Sellens, J., Boada-Grau, J., \& Hontangas-Beltran, P. (2018). The Spanish Version of the Job Crafting Scale. Psicothema,

136-142. https://doi.org/10.7334/psicothema2016.293

Barrett, P. (2007). Structural equation modelling: Adjudging model fit. Personality and Individual differences, 42(5), 815-824. https://doi.org/10.1016/j.paid.2006.09.018 individual job performance; which are some differences between the self-reported evaluation and reported by bosses or colleagues (Ford et al., 2011).

Job crafting is a construct related to the well-being and job performance of workers, however, these relationships are moderated by cultural practices such as collectivism in the group, future orientation, performance orientation and the avoidance of uncertainty (Boehnlein \& Baum (2020). We provide a measure that helps to continue the development of studies on job crafting in different cultures.

It should be noted that the convergence between the findings of this research, and the results of the work of Bakker et al. (2018) for the case of Spain, provides evidence in favor of an applicability of the JC scale, and the revised tetrafactorial model, to the group of Spanish-speaking countries. However, more validation and measurement equivalence studies are required to be able to confirm this thesis more rigorously. In this vein, new studies between two, or more, countries in the region would allow progress in the construction of methodological consensus around the measurement of job redesign behaviors or job crafting, which would not only contribute to research in psychology, but, also, as a result of a more robust knowledge, to the construction of more effective strategies for the promotion of occupational health.

\section{Funding.}

- Fondo Nacional de Financiamiento para la Ciencia, la Tecnología e Innovación (FCTEI), a part of the Colombian Sistema General De Regalías SGR. Convocatoria No. 755 para la Gobernación del Tolima.

- Universidad del Norte, Barranquilla (Colombia), Scholarship for Oscar Iván Gutiérrez Carvajal.

Acknowledgment.-Universidad de Ibagué, Ibagué (Colombia) patrocinador del proyecto de investigación "Característica de la gestión humana relacionada con el bienestar de los empleados". Ibagué, Colombia

Universidad Pontificia Saleciana del Ecuador, Quito (Ecuador), por su participación en todo momento en el proyecto de investigación, y los recursos que fueron otorgados a los autores con afiliación.

Beauducel, A., \& Wittmann, W. W. (2005). Simulation study on fit indexes in CFA based on data with slightly distorted simple structure. Structural Equation Modeling, 12(1), 41-75. https://doi.org/10.1207/s15328007sem1201_3

Berg, J., \& Dutton, J. (2008). Ann Arbor, MI: University of Michigan, Ross School of Business (2008): 1-8. ISBN: 9781616741075

Boehnlein, P., \& Baum, M., (2020) Does job crafting always lead to employee well-being and performance? Meta-analytical evidence on the moderating role of societal culture, The International Journal of Human Resource Management, DOI: 10.1080/09585192.2020.1737177

Bollen, K. A. (1989). Structural equations with latent variables. Toronto, Canada: A Wiley-Interscience Publication. ISBN: 111861903X, 9781118619032

Borgogna, N. C., Brenner, R. E., \& McDermott, R. C. (2021). Sexuality and gender invariance of the PHQ-9 and GAD-7: Implications for 16 iden- 
tity groups. Journal of Affective Disorders, 278, 122-130. https://doi.org/10.1016/j.jad.2020.09.069

Buratta, L., Delvecchio, E., Germani, A., \& Mazzeschi, C. (2020). Parental feeding practices across child's weight status: Evidence of the Italian validation of the Child Feeding Questionnaire. Public Health Nutrition, 19. https://doi.org/10.1017/S136898002000381X

Byrne, B. M. (2010): Structural equation modeling with AMOS: Basic concepts, applications, and programming, New York, Routledge. ISBN: 0805863737

Byrne, B. M. (2008). Testing for multigroup equivalence of a measuring instrument: A walk through the process. Psicothema, 20, 872-882. URL: https://reunido.uniovi.es/index.php/PST/article/view/8744

Cassidy, S. (2016). The Academic Resilience Scale (ARS-30): a new multidimensional construct measure. Frontiers in psychology, 7, 1787. https://doi.org/10.3389/fpsyg.2016.01787

Cenciotti, R., Borgogni, L., Callea, A., Colombo, L., Cortese, C., Ingusci, E., Zito, M. (2016). The Italian version of the job crafting scale (JCS). Bolletino di Psicologia Applicata, 28-36. URL: https://ueaeprints.uea.ac.uk/id/eprint/62994/

Chen, F. F. (2007). Sensitivity of goodness of fit indexes to lack of measurement invariance. Structural Equation Modeling: A Multidisciplinary Journal, 14(3), 464-504. https://doi.org/10.1080/10705510701301834

Cheung, G. W., \& Rensvold, R. B. (2002). Evaluating goodness-of-fit indexes for testing measurement invariance Structural Equation Modeling: A Multidisciplinary Journal, 9(2), 233-255. https://doi.org/10.1207/S15328007SEM0902 5

Chinelato, R. S., Ferrerira, M., \& Valentini, F. (2015). Evidence of validity of the Job Crafting Behaviors Scale. Paidéia, 325-332. https://doi.org/10.1590/1982-43272562201506

Churchill, G. A. (1979). A paradigm for developing better measures of marketing constructs. Journal of marketing research, 16(1), 64-73. https://doi.org/10.1177/002224377901600110

Demerouti, E., Bakker, A., Nachreiner, F., \& Schaufeli, W. (2001). The job demands-resources model of burnout. Journal of Applied Psychology, 499512. https://doi.org/10.1037/0021-9010.86.3.499

Díaz, D (2007). La Evaluación del Bienestar: Poder, Procesamiento de la Información y Confianza. El modelo del Estado Completo de Salud [The Wellbeing Assessment: Power, Information Processing and Trust. The model of the Complete State of Health]. Doctoral Thesis. Universidad Autónoma de Madrid, Madrid, España: Departamento de Psicología Social y Metodología, España. https:// repositorio.uam.es/handle/10486/131378

Eguchi, H., Shimazu, A., Bakker, A. B., Tims, M., Kamiyama, K., Hara, Y., Kawakami, N. (2016). Validation of the Japanese version of the job crafting scale. Journal of Occupational Health, 231-240. https://doi.org/10.1539/joh.15-0173-OA

Erez, M. (2010). Culture and job design. Journal of Organizational Behavior, 389-400. https://doi.org/10.1002/job.651

Gregorich, S. E. (2006). Do self-report instruments allow meaningful comparisons across diverse population groups? Testing measurement invariance using the confirmatory factor analysis framework. Medical Care, 44(11(3)), S78. https://doi.org/10.1097/01.mlr.0000245454.12228.8f

Gupta, S., \& Shifali, A. (2019). Validation of Job Crafting Scale in Indian Context. International Journal of Innovative Technology and Exploring Engineering, 2983-2986. http://doi.org/10.35940/ijitee.K2293.0981119

Hagger, M. S., Gucciardi, D. F., \& Chatzisarantis, N. L. (2017). On nomological validity and auxiliary assumptions: The importance of simultaneously testing effects in social cognitive theories applied to health behavior and some guidelines. Frontiers in psychology, 8, 1933. https://doi.org/10.3389/fpsyg.2017.01933

Hakanen, J., \& Roodt, G. (2010). Using the job demands-resources model to predict engagement: Analysing a conceptual model. In A. Bakker, \& M. Leiter, Work Engagement: A handbook of essential theory and research (pp. 102-117). New York: Psychology Press. ISBN: 1136980881

Hornung, S., Rousseau, D., Glaser, J., Angerer, P., \& Weigl, M. (2010). Beyond top-down and bottom-up work redesign: Customizing job content through idiosyncratic deals. Journal of Organizational Behavior, 187-215. https://doi.org/10.1002/job.625

Hutchinson, S. R., \& Olmos, A. (1998). Behavior of descriptive fit indexes in confirmatory factor analysis using ordered categorical data. Structural
Equation Modeling: A Multidisciplinary Journal, 5(4), 344-364. https://doi.org/10.1080/10705519809540111

Kline, R. B. (2005). Principles and practice of structural equation modeling (2nd ed.). New York, NY: Guilford Press. ISBN: 978-1-57230-690-5

Kulik, C., Oldham, G., \& Hackman, J. (1987). Work design as an approach to person-environment fit. Journal of Vocational Behavior, 278-296. https://doi.org/10.1016/0001-8791(87)90044-3

Lazarte, L. A. (2016). El efecto del Job crafting y el rol mediador del burnout y el engagement sobre la relación entre las caracteristicas laborales y la intención de rotar. TThe effect of Job crafting and the mediating role of burnout and engagement on the relationship between job characteristics and the intention to rotate].Universidad del Pacifico. URI: http://hdl.handle.net/11354/1471

LePine, J., Podsakoff, N., \& LePine, M. (2005). A meta-analytic test of the challenge stressor-hindrance stressor framework: An explanation for inconsistent relationships among stressor and permornance. Academy of Management Journal, 48(5) 764-775. URI: https://www.jstor.org/stable/20159696?seq=1

Lichtenthaler, P., \& Fischbach, A. (2016). The Conceptualization and Measurement of Job Crafting. Validation of a German Version of the Job Crafting Scale. Zeitschrift für Arbeits- und Organisationspsychologie, 173186. https://doi.org/10.1026/0932-4089/a000219

Lichtenthaler, P., \& Fischbach, A. (2019) A meta-analysis on promotionand prevention-focused job crafting, European Journal of Work and Organizational Psychology, 28:1, 30-50, DOI: 10.1080/1359432X.2018.1527767

Lloret-Segura, S., Ferreres-Traver, A., Hernández-Baeza, A., \& TomásMarco, I. (2014). El análisis factorial exploratorio de los ítems: una guía práctica, revisada y actualizada. Anales de Psicologíal Annals of Psychology, 30(3), 1151-1169. https://doi.org/10.6018/analesps.30.3.199361

Lu, C. qin, Wang, H. jiang, Lu, J. jing, Du, D. yang, \& Bakker, A. B. (2014). Does work engagement increase person-job fit? The role of job crafting and job insecurity. Journal of Vocational Behavior, 84(2), 142-152. https://doi.org/10.1016/j.jvb.2013.12.004

Medrano, L. A., \& Muñoz-Navarro, R. (2017). Aproximación conceptual y práctica a los modelos de ecuaciones estructurales. Revista digital de investigación en docencia universitaria, 11(1), 219-239. http://dx.doi.org/10.19083/ridu.11.486

Milfont, T. L., \& Fischer, R. (2010). Testing measurement invariance across groups: Applications in cross-cultural research. International Journal of $p s y$ chological research, 3(1), 111-130. https://doi.org/10.21500/20112084.857

Motl, R. W., \& Conroy, D. E. (2000). Confirmatory factor analysis of the physical self-efficacy scale with a college-aged sample of men and women. Measurement in Physical Education and Exercise Science, 4(1), 13-27. https://doi.org/10.1207/S15327841Mpee0401_3

Nadin, S., Waterson, P., \& Parker, S. (2001). Participation in job redesign: An evaluation of the use of a sociotechnical tool and its impact. Human Factors and Ergonomics in Manufactoring \& Service Industries, 53-69. https://doi.org/10.1002/1520-6564(200124)11:1<53::AIDHFM4>3.0.CO;2-F

Nevitt, J., \& Hancock, G. R. (2001). Performance of bootstrapping approaches to model test statistics and parameter standard error estimation in structural equation modeling. Structural equation modeling, 8(3), 353-377. URL: https://www.tandfonline.com/doi/abs/10.1207/ S15328007SEM0803 2

Oviedo, H. C., \& Arias, A. C. (2005). Aproximación al uso del coeficiente alfa de Cronbach. Revista Colombiana de Psiquiatría, 34(4), 572-580. URL: https://www.redalyc.org/pdf/806/80634409.pdf

Parker, S., \& Collins, C. (2010). Taking stock: integratin and differentiating multiple proactive behaviors. Journal of Management, 633-662. https://doi.org/10.1177/0149206308321554

Putnick, D. L., \& Bornstein, M. H. (2016). Measurement invariance conventions and reporting: The state of the art and future directions for psychological research. Developmental Review, 41, 71-90. https://doi.org/10.1016/i.dr.2016.06.004

Raykov, T., \& Marcoulides, G. A. (2008). An introduction to applied multivariate analysis. New York, NY: Taylor and Francis. ISBN: 9780429235078

Salessi, S. (2020). Adaptación de la escala de job crafting: evidencias de validez en el contexto laboral argentino [Adaptation of the job crafting 
scale: evidence of validity in the Argentine labor context.]. Psicodebate, 20(1), 7-29. https://doi.org/10.18682/pd.v20i1.939

Schaufeli, W., Bakker, A., \& Van Rhenen, W. (2009). How changes in job demads and resources predict burnout, work engagement, and sickness absenteeism. Journal of Organizational Behavior, 893-917. https://doi.org/10.1002/job.595

Schermelleh-Engel, K., Moosbrugger, H., \& Müller, H. (2003). Evaluating the fit of structural equation models: Tests of significance and descriptive goodness-of-fit measures. Methods of psychological research online, $8(2)$

$23-74$. http://www.stats.ox.ac.uk/ snijders/mpr_Schermelleh.pdf

Slemp, G., \& Vella-Brodrick, D. (2104). Optimising employee mental heath: The relationship between intrinsic nedd satisfaction, job crafting, and employee well-being. Journal of Happiness Studies, 957-977. doi:10.1007/s10902-013-9458-3

Sora, B., Caballero, A., \& García-Budas, E. (2018). Validation of Short Form of Job Crafting Scale in a Spanish Sample. The Spanish Journal of Psychology, 1-3. https://doi.org/10.1017/sip.2018.52

Steiger, J. H. (2007). Understanding the limitations of global fit assessment in structural equation modeling. Personality and Individual differences, 42(5), 893-898. https://doi.org/10.1016/i.paid.2006.09.017

Stevanovic, D. (2009). Serbian KINDL questionnaire for quality of life assessments in healthy children and adolescents: reproducibility and construct validity. Health and quality of life outcomes, 7(1), 1-7. https://doi.org/10.1186/1477-7525-7-79

Tims, M., Bakker, A., \& Derks, D. (2012). Development and validation of the job crafting scale. Journal of Vocational Behavior, 173-186. https://doi.org/10.1016/j.jvb.2011.05.009

Tims, M., Bakker, A. B., \& Derks, D. (2014). Job crafting and job performance: A longitudinal study. European Journal of Work and Organizational Psychology, 24(6),

914-928. https://doi.org/10.1080/1359432X.2014.969245

Van Windergen, J., Bakker, A., \& Derks, D. (2016). A test of a job demands-resources intervention. Journal of Managerial Psychology, 686-701. http://dx.doi.org/10.1108/JMP-03-2014-0086
Vogt, K., Hakanen, J., Brauchli, R., Jenny, G., \& Bauer, G. (2016). The consequences of jobcrafting: A three-wave study. Europea Journal of Work and Organizational Psychology. https://doi.org/10.1080/1359432X.2015.1072170

Van de Schoot, R., Lugtig, P., \& Hox, J. (2012). A checklist for testing measurement invariance. European Journal of Developmental Psychology, 9(4), 486-492. https://doi.org/10.1080/17405629.2012.686740

Vecchione, M., Caprara, G. V., Caprara, M. G., Alessandri, G., Tabernero, C. Y González-Castro, J. L. (2014): “The Perceived Political Self Efficacy Scale-Short Form (PPSE-S): A Validation Study in Three Mediterranea Countries", Cross-Cultural Research, 48(4), pp. 368-384. https://doi.org/10.1177/1069397114523924

Ventura-León, J. L., \& Caycho-Rodríguez, T. (2017). El coeficiente Omega: un método alternativo para la estimación de la confiabilidad [The Omega coefficient: an alternative method for estimating reliability]. Revista Latinoamericana de Ciencias Sociales, Niñer y Juventud, 15(1), 625-627. URL: https://www.redalyc.org/pdf/773/77349627039.pdf

Yoo, B. (2002). Cross-group comparisons: A cautionary note. Psychology \& Marketing, 19(4), 357-368. https://doi.org/10.1002/mar.10014

Yoon, M., \& Lai, M. H. (2018): "Testing factorial invariance with unbalanced samples", Structural Equation Modeling: A Multidisciplinary Journal, $25(2), \quad 2012$ https://doi.org/10.1080/10705511.2017.1387859

Wrzesniewski, A., \& Dutton, J. (2001). Crafting a job: Revisioning employees as active crafters of their work. Academy of Management Review, 179-201. https://doi.org/10.2307/259118

Zumárraga-Espinosa, M. (2020). Aportes metodológicos para la medición del sentido de eficacia politica: Evidencia empírica de Quito-Ecuador. [Methodological contributions for measuring the sense of political efficacy: Empirical evidence from Quito-Ecuador]. Empiria. Revista de metodologia de ciencias sociales, (45), 113-142. https://doi.org/10.5944/empiria.45.2020.26306 